\title{
Impact of Using Drones in Emergency Medicine: What Does the Future Hold?
}

\author{
Anna M Johnson (ID' \\ Christopher J Cunningham $\mathbb{D}^{2}$ \\ Evan Arnold (iD ${ }^{3}$ \\ Wayne D Rosamond (D) \\ Jessica K Zègre-Hemsey (iD) 4 \\ 'Department of Epidemiology, Gillings \\ School of Global Public Health, \\ University of North Carolina at Chapel \\ Hill, Chapel Hill, NC, USA; ${ }^{2}$ Department \\ of Emergency Medicine, Henry Ford \\ Hospital, Detroit, MI, USA; ${ }^{3}$ Institute for \\ Transportation Research and Education, \\ North Carolina State University, Raleigh, \\ NC, USA; ${ }^{4}$ School of Nursing, University \\ of North Carolina at Chapel Hill, Chapel \\ Hill, NC, USA
}

\begin{abstract}
The use of unmanned aerial vehicles or "drones" has expanded in the last decade, as their technology has become more sophisticated, and costs have decreased. They are now used routinely in farming, environmental surveillance, public safety, commercial product delivery, recreation, and other applications. Health-related applications are only recently becoming more widely explored and accepted. The use of drone technology in emergency medicine is especially promising given the need for a rapid response to enhance patient outcomes. The purpose of this paper is to describe some of the main current and expanding applications of drone technology in emergency medicine and to describe challenges and future opportunities. Current applications being studied include delivery of defibrillators in response to out-of-hospital cardiac arrest, blood and blood products in response to trauma, and rescue medications. Drones are also being studied and actively used in emergency response to search and rescue operations as well as disaster and mass casualty events. Current challenges to expanding their use in emergency medicine and emergency medical system (EMS) include regulation, safety, flying conditions, concerns about privacy, consent, and confidentiality, and details surrounding the development, operation, and maintenance of a medical drone network. Future research is needed to better understand end user perceptions and acceptance. Continued technical advances are needed to increase payload capacities, increase flying distances, and integrate drone networks into existing 9-1-1 and EMS systems. Drones are a promising technology for improving patient survival, outcomes, and quality of life, particularly for those in areas that are remote or that lack funds or infrastructure. Their cost savings compared with ground transportation alone, speed, and convenience make them particularly applicable in the field of emergency medicine. Research to date suggests that use of drones in emergency medicine is feasible, will be accepted by the public, is cost-effective, and has broad application.
\end{abstract}

Keywords: drone, unmanned aerial vehicle, emergency medicine, emergency medical services

\section{Introduction}

Since the first concept of an unmanned aerial vehicle (UAV) was used in 1849 when Austria attacked Venice using unmanned balloons carrying explosives, the design and application of autonomous or remotely controlled aircraft, or "drones," have modernized dramatically. ${ }^{1,2}$ Drones with a wider spectrum of applications have expanded in the last decade, when electronic technology became more sophisticated, costs of cameras, microphones, speakers, and sensors decreased, and battery power improved, allowing for longer flights, higher payloads, and lower costs. ${ }^{3}$ They are now used routinely in farming (eg, monitoring crop growth or pest infestation), environmental services (eg, tracking of animal populations), public
Correspondence: Anna M Johnson Department of Epidemiology, Gillings School of Global Public Health, University of North Carolina at Chapel Hill, 123 W Franklin St, Suite 4I0, Chapel Hill, NC, 27516 USA

Tel +704 929-0314

Email anna.johnson@unc.edu 
safety (eg, conducting surveillance), commercial product delivery (eg, Amazon packages), recreation, real-estate photography, and in other applications. ${ }^{4}$ Health-related applications are only recently becoming more widely explored and accepted.

The first Federal Aviation Administration (FAA)approved delivery drone in the United States (US) brought medical supplies to a rural Virginia clinic in $2016 ;{ }^{5}$ since then, the use of medical drones has expanded. Medical drones are now used in a wide range of medical and public health situations to supplement ground response teams and manned aircraft, particularly in situations in which responders may be in danger or in which manned air or ground vehicles are costly. For example, drones are now used in the surveillance of natural disaster sites or areas with biological hazards (eg, earthquakes, floods, forest fires), epidemiological surveillance for the detection and monitoring of disease spread (eg, COVID-19, Ebola, Dengue) ${ }^{6}$ or injury prevention (eg, beach surveillance to identify sharks or struggling swimmers). ${ }^{7}$ Hospitals have begun using drones to rapidly and reliably transport laboratory samples, ${ }^{8,9}$ and humanitarian aid organizations are now using drones to cost-effectively bring blood products, vaccines, pharmaceuticals, medical supplies, and even organs to remote, rural areas or areas with poor infrastructure. ${ }^{10-13}$

Worldwide, the use of medical drones has grown rapidly during the COVID-19 pandemic, where face-toface contact is avoided for infection control. During the pandemic, drones have been used for contactless delivery of personal protective equipment (PPE), COVID-19 tests, lab samples, and vaccines. ${ }^{11}$ They have even been used to conduct telemedicine to evaluate patients remotely using drones fitted with two-way video communication devices and sensors to monitor temperature, pulse rate, and respiratory rate. ${ }^{14}$ Drones have also been used to monitor compliance with quarantine orders. ${ }^{15}$

The application of drone technology in emergency medicine is especially promising given the inherent need for a rapid response to enhance patient outcomes. In particular, the use of drones is highly applicable for rapid delivery of medical equipment and medicines for patient selfadministration or by a non-medical (lay) bystander. Additionally, the use of aerial cameras can aid in quick assessment and enhance timely emergency response. For example, drones can augment ambulance response and initiate patient evaluation and treatment more rapidly than ambulance response alone. This use would particularly benefit patients in areas with historically long Emergency Medical Services
(EMS) response times. The purpose of this paper is to describe some of the main current and expanding applications of drone technology in emergency medicine and to describe future challenges and opportunities.

\section{Drones in Emergency Medicine and EMS}

EMS is a core component of the emergency medical and trauma care system, rapidly responding to and transporting millions of Americans every year. ${ }^{16,17}$ Prehospital assessment, care initiation, stabilization, and transportation are critical in the chain of patient survival. Prolonged EMS response and scene times are associated with worse outcomes in patients with significant traumatic injury and shock. ${ }^{18-22}$ Some time-critical medical emergencies, such as cardiac arrest and stroke, depend on prompt EMS response to optimize chances for neurologically intact survival. ${ }^{18}$ Although EMS stations are placed in locations to optimize access to the population they serve, the median EMS arrival times in the US for all call types are between 7 and 8 minutes. ${ }^{18}$ This response time can average more than 14 minutes in rural, remote, geographically challenged, or high-traffic urban areas. ${ }^{23-26}$ Currently, one in ten patients in rural areas waits nearly 30 minutes for EMS arrival. $^{18}$

Changes in the US healthcare system have further complicated timely EMS response and patient outcomes, including trauma center closures, particularly in rural areas. ${ }^{27}$ Additionally, a shift in the funding of EMS from the federal government to states and localities has led to increased fragmentation and variability in the type, quality, and availability of prehospital care. ${ }^{16}$ During the COVID19 pandemic, public hesitancy to interface with the medical system, ${ }^{28}$ provide lay care, and be exposed to potential infection has resulted in delayed initiation of 9-1-1 calls, delayed patient care, and increased EMS response times. ${ }^{29}$

EMS is consistently seeking new and better ways to safely decrease response times and improve patient outcomes. ${ }^{16}$ Advances in healthcare delivery and technology offer new opportunities for innovative solutions. Drones have emerged as a particularly promising innovation.

\section{Delivery of Automated External Defibrillators (AEDs)}

Approximately 350,000 individuals have an out-ofhospital cardiac arrest (OHCA) in the US each year, with survival at around only $10 \%$, despite advances in 
emergency cardiac care. ${ }^{30}$ Survival probability doubles when a bystander conducts defibrillation and cardiopulmonary resuscitation (CPR) prior to EMS arrival. ${ }^{31}$ However, time is of the essence. Likelihood of neurologically intact survival decreases by $10 \%$ for every minute without resuscitation and is highest when CPR and defibrillation are conducted within five minutes of the OHCA. ${ }^{32}$ In rural areas, EMS arrival time is considerably more than the median US arrival time of eight minutes, and can be more than 30 minutes. $^{33}$ Bystander use of AEDs has the potential to improve survival, yet bystander AED use in the US remains at less than $2 \%$, despite programs to increase their use in public areas. ${ }^{31}$ AEDs remain difficult to locate and are rarely available in homes or residential areas, where approximately $70 \%$ of OHCA occur. ${ }^{34,35}$

Recent mathematical modeling studies in the US and in Europe suggest that drones are capable of delivering AEDs rapidly and reliably to a bystander while awaiting EMS arrival. In Toronto, Canada, Boutilier et al used mathematical models to compare historical 9-1-1 response times to a theoretical drone network. They estimated that drones could reduce the 90th percentile of the AED arrival times by over six and ten minutes in urban and rural areas, respectively. ${ }^{36}$ Similarly, Pulver et al reported that while only $4.3 \%$ of OHCAs are reached within one minute by EMS in Salt Lake County, Utah, $80.1 \%$ could be reached within this time if drones were dispatched from existing EMS sites. ${ }^{37}$ Bogle et al found that, if a 500-drone network deployed drones from existing EMS facilities across North Carolina, the median time of AED arrival could be decreased by five minutes and survival rates could be doubled. ${ }^{38}$ Mackle et al likewise describe a country-wide algorithmic approach to design an aerial AED-drone network, coordinated among historical OHCA locations, fixed public AEDs retrievable by lay rescuers, and ground EMS stations with ambulance response. ${ }^{39}$ The program compared fixed AED versus ground EMS versus simulated drone site determine where to station drones across Northern Ireland. A final model of 78 drone bases was chosen to ensure a nationwide standard $(\sim 100 \%)$ of AED arrival to a victim in under eight minutes, but also found almost $50 \%$ of OHCAs having an AED arrival in under three minutes.

OHCA simulation studies have confirmed the feasibility and time-saving potential of drone-delivered AEDs. In Sweden, Claesson et al compared historical EMS times for 18 OHCA events with drone flight times to these sites. ${ }^{40}$
They found that drone-AED delivery times were shorter than historical EMS arrival times in all tests, with a median time savings of more than 16 minutes. In Ontario, Canada, Cheskes et al conducted 6 simulation tests in two rural communities comparing drone and ambulance delivery times of an AED. In all simulated tests, the drone delivered the AED 1.8 to 8.0 minutes faster than the ambulance. ${ }^{41}$ In a US-based study involving 35 simulation tests, Rosamond et al found that drones were able to autonomously deliver AEDs to the site of a simulated OHCA and faster than a pedestrian was able to locate and retrieve and AED in a community setting. ${ }^{42}$ These findings suggest that drones may provide more timely access to early defibrillation for OHCA compared to a bystander ground search for AEDs, even in areas with a high density of public access AEDs. Further, in all five study zones in this study, median AED delivery time by drone was less than the national median EMS arrival time of eight minutes. Findings suggest that AED-equipped drones can be used to augment traditional EMS response to OHCAs in rural, remote, or other areas where EMS arrival times are prolonged.

In 2021, Schierbeck et al delivered AEDs by drone to a series of 12 real-life suspected OCHAs through an area of controlled airspace in Sweden. ${ }^{43}$ Covering a mean distance of 3.1 miles, 11 of the 12 flights successfully dropped the AED by parachute within 9 meters of their intended target (92\%). Of these, 64\% delivered the AED before ambulance arrival, with a mean time savings of 1:52 minutes. This pilot study was the first to demonstrate the feasibility of integrating a drone-delivery system from the OHCA emergency call, to drone dispatch, to AED delivery.

\section{Delivery of Emergency Blood and Blood Products}

Uncontrolled hemorrhage is the leading cause of preventable death in trauma ${ }^{44}$ and timely transfusion of blood has been shown to improve survival. ${ }^{45,46}$ The timely use of blood products (eg, packed red blood cells [PRBCs], plasma, platelets) and whole blood has been shown to decrease mortality in trauma patients. ${ }^{12}$ Studies have demonstrated the feasibility of rapid and reliable dronetransport of blood products while maintaining appropriate storage temperature without significant impact on the accuracy of routine chemistry, hematology and coagulation analysis. ${ }^{10,47,48}$ In Rwanda, drone technology is 
already being used to cost-effectively deliver whole blood in trauma events as well as in maternal/obstetric emergencies such as postpartum hemorrhage, which is the cause of one in four maternal deaths worldwide. ${ }^{49}$ In Ghana, drone delivery of blood (both as lab samples and as emergency blood and blood product delivery) is now available for thousands of health facilities serving millions of people. $^{11}$ In the US, where whole blood and blood products are often sparse in rural areas, and where drones are more highly regulated and where air traffic is more congested, the feasibility of drone-delivery of blood and blood products is still being assessed. ${ }^{12}$ Homier et al demonstrated the feasibility and time savings of drone delivery compared with ground transport of temperature-controlled simulated blood samples to densely populated urban areas in a recent simulation study. ${ }^{50}$

\section{Delivery of Rescue Medications}

Early administration of naloxone is a US Food and Drug Administration (FDA)-approved antidote to opioid overdose (OD). While nasal spray naloxone is publicly available, less than $5 \%$ of bystanders witnessing an opioid OD administer this antidote to an OD victim in the US. ${ }^{51}$ A potential solution, particularly in areas with historically long response times, is to dispatch a naloxone-equipped drone concurrent with ambulance dispatch. In a recent feasibility study involving 30 simulated OD events, Ornato et al found that all participants successfully followed the simulated 9-1-1 dispatcher instructions accurately and administered the intranasal naloxone medication successfully to the manikin within approximately two minutes of initial 9-1-1 contact. $^{52}$ Further, $97 \%$ of participants reported feeling confident they could administer the intranasal naloxone to an opioid OD victim in a real event.

Drones have also been evaluated as potential modes of emergency delivery of rescue medicines such as epinephrine, antiepileptics, and insulin. Early administration of epinephrine is the only first-line medication for anaphylaxis treatment and is routinely delivered by patients themselves or lay bystanders using an EpiPen ${ }^{\circledR}$ or similar delivery system. ${ }^{53}$ Beck et al demonstrated that EpiPens ${ }^{\circledR}$ can be feasibly transported by drone without pharmacological changes. ${ }^{53}$ Mateen et al found that antiepileptic drugs could be feasibly and reliably delivered by a drone for both emergency/status epilepticus and non-urgent distribution in the capital of the Republic of Guinea to preidentified delivery stations. ${ }^{54}$ Further, they found that a drone reduced the average delivery time by $78.8 \%$. Similarly, Hii et al demonstrated that products containing insulin-which can be administered to patients who require rapid and efficient control of hyperglycemia due to diabetes or another condition - can be transported by drone without pharmacological changes. ${ }^{55}$ Drones have also been hypothesized to be feasible delivery systems for other emergency medications such as an albuterol inhaler for an acute asthma attack.

\section{Search and Rescue}

One of the many services that EMS provides is Search and Rescue (SAR), which can be particularly critical in remote or coastal areas. The viability of using drones to aid deployed rescuers in remote SAR operations was evaluated in a series of 10 simulated SAR events in remote Utah in $2020 .^{56}$ In this study, McRae et al tested the ability of drones to maintain radio communication between deployed rescuers and a central command in areas with compromised ground-based radio communication. They found that in all ten areas evaluated, drone assistance restored and maintained consistent lines of communication. Using deep learning, Hungarian researchers Liu and Szirányi (2021) demonstrated that drones have the capability to accurately and reliably recognizing a range of human gestures from a distance that could aid in future SAR operations. ${ }^{57}$

Drones are currently used to assist EMS in the rescue of hikers or skiers in mountainous, heavy snow, and avalanche areas. ${ }^{58,59}$ Rapid rescue in these areas is particularly critical, as odds of survival decrease dramatically after approximately 15 minutes of snow burial. ${ }^{60}$ Although drones do not have the capability to extricate victims from the snow, drones outfitted with thermal or multispectral imaging cameras can detect gases such as carbon dioxide to locate the victim. Response times can be further decreased if the victim is wearing a transceiver that can be detected by the drone. In a Turkish simulation study of 20 SAR simulation comparing "classic" foot searches to a drone search combined with snowmobile-enabled rescue, Karaca et al found that SAR operations could be conducted over longer distances and more rapidly using the drone-snowmobile SAR method. ${ }^{61}$

In coastal areas, rapid EMS response to potential drowning victims is critical; survival is poor 10 minutes after submersion. ${ }^{62}$ In these cases, drones can be used not just for surveillance of potential drowning victims ${ }^{63}$ but to also rapidly locate a distressed swimmer and deliver 
floatation devices. ${ }^{64}$ In a French simulation study, Seguin et al conducted 28 tests and compared response times with and without use of a drone. ${ }^{64}$ They found that drones were able deliver a flotation device to a swimmer safely and quickly in a variety of weather conditions. Further, they found that the addition of a drone to the beachfront operations improved the quality and speed of first aid while keeping lifeguards away from dangerous sea conditions. In a Swedish simulation study, Claesson et al evaluated the speed with which a drone-assisted SAR operation could locate a simulated drowning victim compared to traditional SAR procedures, conducting 10 searches using each SAR method. ${ }^{65}$ Authors reported a median time savings of 3:38 $\mathrm{min}$ (IQR 2:02-6:38) using the drone-assisted search. Further, in a follow-up simulation study, Claesson et al found that a drone, combined with an online machine learning model designed to recognize simulated drowning victims, was able to effectively identify simulated submerged drowning victims in open water. In this study, the authors paired 100 drone photo simulations (100 with drowning victims and 100 without) and demonstrated strong sensitivity (91\%) and specificity (90\%) during favorable environmental conditions. ${ }^{62}$

\section{Disaster Response}

Drones are also used as critical tools in disaster response and management. ${ }^{66}$ In such events, drones can be used to provide emergency surveillance, telecommunication services, SAR operations, and delivery of emergency supplies and aid in areas in which medical personnel are unable to safely reach. For example, drones were able to deliver such emergency medical response and aid to people in Haiti and Taiwan after the 2010 and 2016 earthquakes, in the Philippines after Typhoon Haiyan in 2013, and in Nepal, which faces frequent floods, landslides, and avalanches. ${ }^{67,68}$ In the US, plans to deliver supplies to Ocracoke Island, a remote island village in the Outer Banks of North Carolina, are in the process of being tested for hurricane response scenarios. ${ }^{69}$ Drones equipped with video, telecommunication capabilities, and thermal imaging can be particularly useful in such events. Drones have also been shown to have the potential be particularly valuable tools for disaster management in remote areas such as the Canadian arctic. $^{70}$

\section{Mass Casualty Response}

A mass casualty incident (MCI) is any incident that overwhelms available resources. This dynamic definition allows the term to apply to a range of incidents, such as a complex motor-vehicle accident, an active shooter/assailant with dozens of victims, to a multistate natural disaster. When resources are stretched thin, multiple responding agencies need to coordinate a logical, efficient response by having open lines of communication, and be supervised by a centralized incident command. Often these types of incidents are complicated by disparate agency-command structures, different agency telecommunication-systems, and limited information available to incident command. The Federal Emergency Management Agency (FEMA) outlines the ideal framework and principles for incident management and command hierarchy.

Drones could serve to augment this type of response, allowing the command staff to have direct, visual supervision over the nature of the MCI, ensure scene safety, and assist with operations and logistics of field personnel. ${ }^{71,72}$ An "eye in the sky" may provide invaluable information for command staff that are at a distance from the incident, where historically only radio reports provide situation response. Surveys of incident commanders find that this tool would be valuable to augment this radio information of front-line responders. ${ }^{73}$

Not only can drones augment the command/supervisory role, but they can also influence direct field operations. For example, Jain et al performed a simulation trial of using drones to augment field triage and casualty evacuation and found statistically faster triaging of patients, without a sacrifice in accuracy, in both day and night conditions. $^{71}$ Álvarez-Garcia et al developed an aerial remote triage system. ${ }^{74}$ Drones with loudspeakers can also address crowds, such as directing them to safety or to perform behaviors directed by emergency personnel staff. $^{75}$ One such application may be for direction of mass decontamination in chemical, biological, radiological and nuclear (CBRN) disasters. ${ }^{76}$ In this manner, drones would be a valuable field resource and more cost-efficient than manned aerial emergency response apparatus (eg, helicopters).

\section{Other Remote Emergency Evaluation and Response}

In a recent review of studies investigating the feasibility of using drones to deliver telemedicine, Bhatt et al's study demonstrated that drones may be a feasible and costeffective mechanism for providing emergency telecommunication and telemedicine with patients with otherwise 
limited or delayed access due to distance, geography, or infrastructure. $^{63}$ In particular, drones fitted with two-way video communication and bio-sensors (eg, to measure temperature, heart rate, or blood pressure $)^{14}$ may be particularly applicable for use in telemedicine for diagnosis, evaluation, and even treatment in remote areas.

Drones are even being tested for use as communication hotspot for surgeons to conduct emergency telesurgery in the battlefield where wired communication has been disrupted; ${ }^{77}$ however, due to ethical, technical, clinical, and other concerns, this has not yet extended into the civilian realm. ${ }^{63}$ Similarly, preliminary data suggest that drones can be used to provide "telementoring" of surgical procedures - including those in emergency care - by providing a rapid, stable communication platform for experienced surgeons to remotely guide more proximate surgeons. ${ }^{5,78}$

\section{Current Challenges}

There are a number of challenges to the present landscape of drone usage in emergency medicine. First and foremost are the technologic restraints such as stability of flight, weight, flight time, flight range, the incorporation of machine learning, sensing of barriers and other aircraft, and emergency landing procedures. However, the current market is tackling these limitations with new models, advances, and equipment specifications that. Beyond this, there are a number of domains that impact this growing field: the regulatory framework of this industry, interactions with privacy concerns, safety, feasibility in different aerial conditions, cost and maintenance, and end user experiences and expectations.

\section{Regulation}

Drone regulatory authorities such as the United States' Federal Aviation Administration (FAA) and the European Union's European Aviation Safety Agency (EASA) set the standards for technical, safety, security and administrative issues related to drones in these regions. These authorities are challenged with keeping pace with rapid advances in drone technology in a way that balances safety, privacy, public acceptance, and existing aerial traffic. ${ }^{79,80}$ Together with other government agencies, the FAA and EASA are investing significantly in research to model and assess potential risks of medical drones and are developing regulations to ensure these risks are appropriately managed. ${ }^{81}$ Additionally, in the US, EMS agencies are regulated at the state level, and so there may be regulatory conflicts between state and federal dominion for drone technology.
Because of current drone regulations in the US dictating flight paths and operations, medical drones are currently primarily used only in the research or experimental setting. However, the FAA has been loosening restrictions and providing more opportunities for real-world application.

A current regulatory barrier is the FAA requirement that drones remain within the operator's line of sight. Operators must obtain additional permissions to fly beyond visual line of sight (BVLOS). ${ }^{3}$ Because this regulation is a constraint on so many drone operations, the FAA has created a BVLOS Aviation Rulemaking Committee (ARC) to help lay a path to more operational approval. Until recently, operations of drones over people were similarly restricted; however, new rules have opened the door for more routine flights above populated areas and trafficked roads through various aircraft certification methods. These requirements ensure the reliability of the aircraft is in line with typical risk currently accepted by the aviation industry. Because of this regulatory environment, much of the work with medical delivery drones to date has been conducted in countries such as Rwanda and Ghana, where drone flights are less tightly regulated and where airspace is less congested than in the US, Europe, and other parts of the world.

\section{Privacy, Confidentiality, and Consent}

One of the benefits of medical drones is the ability to communicate remotely with people in need of medical attention; however, this requires the capture and transmission of individuals' protected health information (PHI). Data processing, security, and privacy concerns must be ensured. ${ }^{14,82}$ Specifically, unlike drones used for other purposes (commercial delivery, environmental surveillance, etc.), medical drones must be Health Insurance Portability and Accountability Act (HIPAA) compliant and ensure the protection of confidential and private patient information. In research settings with medical drones, if they are to fly over public gatherings, it raises unique issues related to consent. ${ }^{83}$

Likewise, the American public is skeptical of governmental drones, with strong majorities of surveyed people believing increased use would be an invasion of privacy. ${ }^{80}$ Similarly, privacy concerns were one of the few but significant apprehensions that the Australian public had with the expansion of drone technology. ${ }^{81}$ However, the vast majority of people do approve of drone technology for SAR, climate monitoring and land management. ${ }^{84}$ A discrepancy may exist between the results of 
a hypothetical survey and the real world realized attitudes for privacy concerns when the public cannot discern the function of a drone flying above them. Standardized lights, designs, sirens, colors, or labels may help the public recognize and appreciate the purpose of EMS drones.

To address issues of privacy, confidentiality, and consent, particularly in the research setting, investigators will need to communicate with communities which could be affected by the research. ${ }^{83}$ Further, investigators need to take steps to protect the privacy and confidentiality of bystanders who may not be directly involved in the research or considered human subjects but who may be impacted by the research nevertheless.

\section{Safety}

As with any emerging technology, potential malfunctions are a concern. In the case of autonomous flights, errors may not be able to be resolved while the drone is in flight. ${ }^{63}$ Drones may further be susceptible to hacking, crashing into obstacles (eg, buildings or other aircraft), or rerouting, particularly when reliant on Global Positioning System (GPS) for autonomous flights. ${ }^{63,85}$ To minimize such potential safety hazards, drone flight paths will need to continue to be better integrated into existing FAA and aerial vehicle flight paths and communications (eg, nearby hospital helicopter flights). From a commercial delivery standpoint, Uber is already improving drone integration with other aerial vehicles (planes, helicopters, etc.) by creating a dedicated air-traffic management system through a partnership with NASA. ${ }^{86}$ Other safety concerns include the potential for injury via direct impact with a person if an accident were to occur, as well as the need for safe and secure packaging of potentially hazardous payloads for medical drone operators. ${ }^{87}$ Safety regulations, processes, and operator training will need to be continuously updated, particularly as use of drones increases. ${ }^{50}$

\section{Flying Conditions}

Operational limitations will inevitably affect any drone response technologies. Weather has a significant impact on the entire aviation industry, with unique challenges beyond typical inclement conditions. Factors such as air density, humidity, and temperature can directly impact flight time, payload capacity, and safe flying altitudes. Whereas manned aviation has visual and instrument flight rules to determine what operations are permitted based on current weather conditions, drone operations are mainly restricted by visibility conditions (eg, haze, fog, low clouds), with operators having the final determination regarding precipitation, temperature, and other factors. Future studies are needed to determine how well medical drones perform under varying weather and daylight conditions. $^{35}$

\section{Infrastructure, Operation, and Maintenance}

While simulation studies are able to deploy drones wherever they need for the design of their experiments, widespread drone operations would require installation and maintenance of a network of drone, pilots, and other necessary infrastructure to ensure constant operational availability. Other considerations include the bandwidth of radio frequencies for command and control of the aircraft as well as payload control. On most commercial drones, both of these tasks are done with direct radiofrequency transmissions, due to the proximity of the aircraft to the ground control station or remote controller; however, both satellite and cellular networks are being explored for these communication needs as well.

One of the many benefits of a drone is its ability to provide telecommunication and, in some cases, video communication. This requires communication networks outside of commercial networks. In 2016, Facebook ( began designing a drone system capable of delivering internet and telecommunication services to remote areas without normal internet access. ${ }^{88}$ Although the project was ultimately abandoned, the proof of concept has implications for emergency response for ground personnel if normal telecommunication infrastructure were affected by a disaster.

The creation of an emergency medical drone network would also require the development of a physical, organizational, and operational infrastructure. Bogle et al recently evaluated the feasibility and cost-effectiveness of developing such an infrastructure in the state of North Carolina for the purposes of delivering AEDs to victims of cardiac arrest. ${ }^{38}$ In this study, the authors developed mathematical models to optimize the selection of docking stations, where drones can be protected, charged, and centrally dispatched, and concluded that an AED drone network is both feasible and cost-effective. Diverse community-based studies are still needed, however, to test real-world efficiency, feasibility, acceptability, and security $^{42}$ and to understand how the location of drone 
deployment sites may be impacted by geography, weather, other air traffic, and other factors. ${ }^{35}$

\section{User Acceptance and Perception}

An important next step in moving use of drone technology forward in emergency medicine is getting a better understanding of current public perception of drones and understanding potential facilitators and barriers to increasing lay bystanders' interaction with drones. ${ }^{5}$ To date, few studies have explored public perceptions of drones, particularly in an emergency medical situation. In a set of two surveys conducted in Australia, Clothier et al found that while the Australian public generally considers drones to be safe, privacy and the potential for misuse were common concerns. ${ }^{81}$ In a recent study of lay bystanders interacting directly with AED-equipped drones in a simulated OHCA emergency in a community setting, Rosamond et al and Zègre-Hemsey et al found that participants generally reported positive feedback about their experiences interacting with a drone, and $89 \%$ reported feeling comfortable as the drone approached. ${ }^{42,89}$ Specifically, participants reported AED-equipped drones enabled them to stay with the victim and continue cardiopulmonary resuscitation (CPR) and felt relieved at having life-saving equipment directly delivered. ${ }^{89}$ All participants said they would use a drone-delivered AED in a real-life OHCA emergency. ${ }^{89}$ Similarly, Sanfridson et al reported that the eight bystanders queried experienced AED delivery by drone as both safe and feasible. ${ }^{75}$ Findings suggest that drone delivery of an AED is feasible and acceptable in a community setting but that additional community-based research and public education is needed.

Also important in moving forward routine use of drone technology in emergency medicine is learning more about the current comfort level of EMS and hospital systems in interacting with this technology and incorporating it into current systems of care. Similarly, in order for drone technology to become widespread in the US for emergency care, buy-in from the Centers for Medicare and Medicaid Services (CMS) and insurance companies is needed. For this to happen, not only does the feasibility and safety of emergency medical drones need to be established, but also the cost-effectiveness. The costeffectiveness of building and maintaining optimized drone networks has been studied in a theoretical mathematical model in the state of North Carolina, with the conclusion that an AED drone network would improve cardiac arrest survival and neurological outcomes and be cost-effective over a wide range of assumptions. ${ }^{38}$ Additional cost-effectiveness analyses are needed to establish the level of buy-in needed for insurance coverage of emergency medical drones.

\section{Future Opportunities}

Research to date into the use of medical drones to deliver AEDs, emergency blood products, or rescue medicines, to assist with SAR efforts, disaster or mass casualty response, and to provide a mechanism for emergency telemedicine in challenged areas suggests a broad application for the use of drones in the practice of emergency medicine. More applications have been theorized or are already in the development phases for testing and further research. For example, a drone capable of carrying heavier payloads, including medical personnel, has been developed by the China-based manufacturer Ehang. ${ }^{90}$ However, in the current legal and regulatory environment of many countries, such as the US and Europe, research on this innovative application is not yet feasible. Increasing the payload capacity of drones would also allow for the rapid transport of larger quantities of medications, blood, and blood products. Currently, multiple drones would be required to transport the blood supply carried by a single ground vehicle. ${ }^{50}$ Additional technological advances such as artificial intelligence and longer-life batteries would allow for longer, safer flights.

To advance integration of drones into emergency medical practice, advances are needed beyond drone technology. For example, research is needed to explore the feasibility of integrating drones into EMS and 9-1-1 communication and dispatch systems ${ }^{36,38}$ and incorporating the triaging of emergency calls that would be best responded to with a drone (eg, those with events relevant of response by drone, with longer historical response times, etc). ${ }^{91}$ Autonomous emergency drone flights would also require the development of software that can integrate the drone's destination in real time using Geographic Information System (GIS) tools into the drone's flight plan, while also incorporating other factors into the flight path such as fixed (eg, buildings, etc.) and mobile (eg, other aerial vehicles) obstacles. ${ }^{63}$ Combining drones with machine learning models - and continually optimizing models for safe and rapid emergency response-could lead to further benefits of drone technology. ${ }^{38}$ In addition, if drones were to be successfully integrated into the emergency response system of care, a better understanding would be needed of the drone- 
bystander interaction in the context of 9-1-1 telecommunication and instructions and EMS response. ${ }^{35}$

Future work also needs to explore human-drone interactions in real-world settings. While surveys and simulation studies suggest that the majority of bystanders would be comfortable interacting with medical drones, more research is needed to understand how this might work in practice, particularly in the context of communication with 9-1-1 telecommunicators and in combination of practicing CPR and using an AED, both of which have proven challenging and required public education on their own. The public may have different opinions about these developing usages of drones. However, when implemented, the widespread use of drones may manifest public concerns for safety, privacy, and financial cost.

An emphasis on and evaluation of the ability of medical drone systems to address disparities in access to timely care to persons requiring emergency health-care services in geographically isolated areas-where population density is low and EMS drive times are long-is particularly needed. Populations in remote or rural areas tend to have less access to health-care services, be of older age, and have more comorbidities, which may increase the need for rapid response for conditions such as OHCA or stroke. ${ }^{92,93}$ Rural populations also tend to have a lower average socioeconomic status, putting them at higher risk for conditions such as OHCA. ${ }^{94}$ Indeed, OHCAs in lowincome neighborhoods have 10\% longer average EMS times than those from wealthier neighborhoods ${ }^{95}$ and are $12 \%$ less likely to survive. ${ }^{96}$ Further, OHCAs in lowincome neighborhoods are less likely to be assisted by bystander $\mathrm{CPR}^{94,97}$ or defibrillation. ${ }^{98}$ Delivery of an AED by drone has the potential to increase access to timely defibrillation and provide two-way communication to assist bystanders deliver lifesaving care to OCHA victims in rural and rural areas while they await the arrival of EMS teams.

Bringing drone technology to routine use in emergency medicine will likely be a dynamic process that involves partnerships among academic, private, and government sectors. ${ }^{38}$ Such partnerships have already begun forming. For example, in the US, Zipline has coordinated with NASCAR for landing zone space, the United Parcel Service (UPS) for logistics, and hospital systems to deliver PPE to medical staff during the COVID-19 pandemic. $^{11}$ Similarly, the drone manufacturer Volansi has partnered with the pharmaceutical company Merck and a nonprofit health clinic in rural North Carolina to deliver prescription medications, including asthma inhalers and insulin, and COVID-19 vaccines to seniors living in remote areas. ${ }^{99}$

Drones are a promising technology for improving patient survival, outcomes, and quality of life, particularly for those in areas that are remote or that lack funds or infrastructure. Their cost savings compared with ground transportation alone, speed, and convenience make them particularly applicable in the field of emergency medicine. Research to date suggests that use of drones in emergency medicine is feasible, will be accepted by the public, and has broad application. While they continue to be integrated into commercial activities such as delivery services and recreation, it is important to advocate for their use in medical applications. ${ }^{38}$ To make this potentially lifesaving application of drone technology a reality, more research is needed to put this practice into routine use while navigating a changing regulatory environment, public safety and privacy, and public acceptance. As drones continue to be developed with decreased costs, longer-life batteries, lighter frames, and the capability to carry heavier payloads, as regulatory agencies work to keep pace with the rapid advances in drone technology, and as public acceptance of drones increases, the sky is the limit for the use of drones in emergency medicine.

\section{Acknowledgments}

This work was supported by the National Center for Advancing Translational Sciences (NCATS), National Institutes of Health (NIH), through Grant Award Number UL1TR002489. The content is solely the responsibility of the authors and does not necessarily represent the official views of the NIH.

\section{Disclosure}

The authors report no conflicts of interest in this work.

\section{References}

1. Blom JD. Unmanned Aerial Systems: A Historical Perspective. Occasional Paper 37. Fort Leavenworth, KS: Combat Studies Institute Press; 2010.

2. Prisacariu V. The history and the evolution of UAVs from the beginning till the 70s. J Defense Resour Manage. 2017;8(1):181-189.

3. Cho R. How drones are advancing scientific research; 2017. Available from: https://news.climate.columbia.edu/2017/06/16/how-drones-areadvancing-scientific-research/. Accessed November 3, 2021.

4. Rebolo-Ifrán N, Grilli MG, Lambertucci SA. Drones as a threat to wildlife. Environ Conserv. 2019;46(3):205-210. doi:10.1017/ S0376892919000080

5. Rosser JC, Vignesh V, Terwilliger BA, Parker BC. Surgical and medical applications of drones: a comprehensive review. JSLS. 2018;22(3):e2018.00018. doi:10.4293/JSLS.2018.00018 
6. Tkatek S, Belmzoukia A, Nafai S, Abouchabaka J, Ibnou-Ratib Y. Putting the world back to work: an expert system using big data and artificial intelligence in combating the spread of COVID-19 and similar contagious diseases. Work. 2020;67(3):557-572. doi:10.3233/WOR-203309

7. McNabb H. Drones will patrol beaches in Australia to protect crowds from sharks - and Coronavirus; 2020. Available from: https://drone life.com/2020/11/13/drones-patrol-beaches-in-australia/. Accessed September 30, 2021.

8. Cohen JK. WakeMed health \& hospitals joins forces with UPS, FAA for drone pilot; 2019. Available from: https://www.modernhealthcare. com/care-delivery/wakemed-health-hospitals-joins-forces-ups-faadrone-pilot. Accessed September 30, 2021.

9. Peck AD. Hospitals in United States and Germany team up with matternet and UPS to make medical laboratory deliveries by drone the new normal; 2021. Available from: https://www.darkdaily.com/ 2021/08/11/hospitals-in-united-states-and-germany-team-up-withmatternet-and-ups-to-make-medical-laboratory-deliveries-by-dronethe-new-normal/. Accessed September 30, 2021.

10. Poljak M, Šterbenc A. Use of drones in clinical microbiology and infectious diseases: current status, challenges and barriers. Clin Microbiol Infect. 2020;26(4):425-430. doi:10.1016/j.cmi.2019.09.014

11. Bright J. Zipline begins US medical delivery with drone program honed in Africa; 2020. Available from: https://techcrunch.com/2020/ 05/26/zipline-begins-us-medical-delivery-with-uav-program-honedin-africa/. Accessed September 30, 2021.

12. Thiels CA, Aho JM, Zietlow SP, Jenkins DH. Use of unmanned aerial vehicles for medical product transport. Air Med J. 2015;34 (2):104-108. doi:10.1016/j.amj.2014.10.011

13. Scalea JR, Restaino S, Scassero M, Bartlett ST, Wereley N. The final frontier? Exploring organ transportation by drone. Am J Transplant. 2019;19(3):962-964. doi:10.1111/ajt.15113

14. Kumar A, Sharma K, Singh H, Naugriya SG, Gill SS, Buyya R. A drone-based networked system and methods for combating coronavirus disease (COVID-19) pandemic. FGCS. 2021;115:1-19. doi:10.1016/j.future.2020.08.046

15. Greenwood F. Assessing the impact of drones in the global COVID response; 2021. Available from: https://www.brookings.edu/tech stream/assessing-the-impact-of-drones-in-the-global-covid-response/. Accessed September 30, 2021.

16. Institute of Medicine. Emergency Medical Services: At the Crossroads. Washington, DC: The National Academies Press; 2007.

17. National Highway Traffic Safety Administration (NHTSA). Strategy for a national EMS culture of safety; 2013. Available from: https:// www.ems.gov/pdf/Strategy-for-a-National-EMS-Culture-of-Safety -10-03-13.pdf. Accessed September 30, 2021.

18. Mell HK, Mumma SN, Hiestand B, Carr BG, Holland T, Stopyra J. Emergency medical services response times in rural, suburban, and urban areas. JAMA Surg. 2017;152(10):983-984. doi:10.1001/ jamasurg.2017.2230

19. Cowley RA. A total emergency medical system for the State of Maryland. Md State Med J. 1975;24(7):37-45.

20. Wyatt J, Beard D, Gray A, Busuttil A, Robertson C. The time of death after trauma. BMJ (Clinical Research Ed). 1995;310 (6993):1502. doi:10.1136/bmj.310.6993.1502

21. Harmsen AM, Giannakopoulos GF, Moerbeek PR, Jansma EP, Bonjer HJ, Bloemers FW. The influence of prehospital time on trauma patients outcome: a systematic review. Injury. 2015;46 (4):602-609. doi:10.1016/j.injury.2015.01.008

22. Nasser AAH, Nederpelt C, El Hechi M, et al. Every minute counts: the impact of pre-hospital response time and scene time on mortality of penetrating trauma patients. Am J Surg. 2020;220(1):240-244. doi:10.1016/j.amjsurg.2019.11.018

23. Larsen MP, Eisenberg MS, Cummins RO, Hallstrom AP. Predicting survival from out-of-hospital cardiac arrest: a graphic model. Ann Emerg Med. 1993;22(11):1652-1658. doi:10.1016/S0196-0644(05) $81302-2$
24. Valenzuela TD, Roe DJ, Nichol G, Clark LL, Spaite DW, Hardman RG. Outcomes of rapid defibrillation by security officers after cardiac arrest in casinos. $N$ Engl $J$ Med. 2000;343 (17):1206-1209. doi:10.1056/NEJM200010263431701

25. Waalewijn RA, de Vos R, Tijssen JG, Koster RW. Survival models for out-of-hospital cardiopulmonary resuscitation from the perspectives of the bystander, the first responder, and the paramedic. Resuscitation. 2001;51 (2):113-122. doi:10.1016/S0300-9572(01)00407-5

26. Hanna M. Utility of unmanned aircraft systems in inner city emergent response during peak rush hour traffic. Pediatrics. 2020;146(1 MeetingAbstract): 183 .

27. Hsia RY, Shen YC. Rising closures of hospital trauma centers disproportionately burden vulnerable populations. Health Aff (Project Hope). 2011;30(10):1912-1920. doi:10.1377/hlthaff.2011.0510

28. Garcia S, Albaghdadi MS, Meraj PM, et al. Reduction in ST-segment elevation cardiac catheterization laboratory activations in the United States during COVID-19 pandemic. J Am Coll Cardiol. 2020;75 (22):2871-2872. doi:10.1016/j.jacc.2020.04.011

29. Uy-Evanado A, Chugh HS, Sargsyan A, et al. Out-of-hospital cardiac arrest response and outcomes during the COVID-19 pandemic. JACC Clin Electrophysiol. 2021;7(1):6-11.

30. Virani SS, Alonso A, Aparicio HJ, et al. Heart disease and stroke statistics-2021 update: a report from the American Heart Association. Circulation. 2021;143(8):e254-e743.

31. Weisfeldt ML, Everson-Stewart S, Sitlani C, et al. Ventricular tachyarrhythmias after cardiac arrest in public versus at home. N Engl J Med. 2011;364(4):313-321. doi:10.1056/NEJMoa1010663

32. Kleinman ME, Brennan EE, Goldberger ZD, et al. Part 5: adult basic life support and cardiopulmonary resuscitation quality: 2015 American Heart Association guidelines update for cardiopulmonary resuscitation and emergency cardiovascular care. Circulation. 2015;132(18 Suppl 2): S414-435. doi:10.1161/CIR.0000000000000259

33. Nichol G, Thomas E, Callaway CW, et al. Regional variation in out-of-hospital cardiac arrest incidence and outcome. JAMA. 2008;300(12):1423-1431. doi:10.1001/jama.300.12.1423

34. Johnson AM, Cunningham CJ, Zégre-Hemsey JK, et al. Out-of-hospital cardiac arrest bystander defibrillator search time and experience with and without directional assistance: a randomized simulation trial in a community setting. Simul Healthc. 2021. doi:10.1097/SIH.000 0000000000582

35. Zègre-Hemsey JK, Bogle B, Cunningham CJ, Snyder K, Rosamond W. Delivery of automated external defibrillators (AED) by drones: implications for emergency cardiac care. Curr Cardiovasc Risk Rep. 2018;12. doi:10.1007/s12170-018-0589-2

36. Boutilier JJ, Brooks SC, Janmohamed A, et al. Optimizing a drone network to deliver automated external defibrillators. Circulation. 2017;135 (25):2454-2465. doi:10.1161/CIRCULATIONAHA.116.026318

37. Pulver A, Wei R, Locating MC. AED enabled medical drones to enhance cardiac arrest response times. Prehosp Emerg Care. 2016;20 (3):378-389. doi:10.3109/10903127.2015.1115932

38. Bogle BM, Rosamond WD, Snyder KT, Zègre-Hemsey JK. The case for drone-assisted emergency response to cardiac arrest: an optimized statewide deployment approach. NC Med J. 2019;80(4):204-212.

39. Mackle $\mathrm{C}$, Bond R, Torney $\mathrm{H}$, et al. A data-driven simulator for the strategic positioning of aerial ambulance drones reaching out-ofhospital cardiac arrests: a genetic algorithmic approach. IEEE $J$ Transl Eng Health Med. 2020;8:1900410. doi:10.1109/ JTEHM.2020.2987008

40. Claesson A, Backman A, Ringh M, et al. Time to delivery of an automated external defibrillator using a drone for simulated out-ofhospital cardiac arrests vs emergency medical services. JAMA. 2017;317(22):2332-2334. doi:10.1001/jama.2017.3957

41. Cheskes S, McLeod SL, Nolan M, et al. Improving access to automated external defibrillators in rural and remote settings: a drone delivery feasibility study. J Am Heart Assoc. 2020;9(14):e016687. doi:10.1161/JAHA.120.016687 
42. Rosamond WD, Johnson AM, Bogle BM, et al. Drone delivery of an automated external defibrillator. $N$ Engl $J$ Med. 2020;383 (12):1186-1188. doi:10.1056/NEJMc1915956

43. Schierbeck S, Hollenberg J, Nord A, et al. Automated external defibrillators delivered by drones to patients with suspected out-of-hospital cardiac arrest. Eur Heart J. 2021;42. doi:10.1093/eurheartj/ehab724.0656

44. Kornblith LZ, Moore HB, Cohen MJ. Trauma-induced coagulopathy: the past, present, and future. J. Thromb Haemost. 2019;17 (6):852-862. doi: $10.1111 /$ jth. 14450

45. Gilmore CK, Chaykowsky M, THomas B; Rand Corporatoin. Autonomous Unmanned Aerial Vehicles for Blood Delivery: A UAV Fleet Design Tool and Case Study. Santa Monica, CA: Rand Corporation; 2019.

46. Shackelford SA, Del Junco DJ, Powell-Dunford N, et al. Association of prehospital blood product transfusion during medical evacuation of combat casualties in Afghanistan with acute and 30-day survival. JAMA. 2017;318(16):1581-1591. doi:10.1001/jama.2017.15097

47. Amukele TK, Sokoll LJ, Pepper D, Howard DP, Street J. Can unmanned aerial systems (drones) be used for the routine transport of chemistry, hematology, and coagulation laboratory specimens? PLoS One. 2015;10(7):e0134020. doi:10.1371/journal.pone.0134020

48. Amukele T, Ness PM, Tobian AA, Boyd J, Street J. Drone transportation of blood products. Transfusion. 2017;57(3):582-588. doi:10.1111/trf.13900

49. Zailani MAH, Sabudin R, Rahman RA, Saiboon IM, Ismail A, Mahdy ZA. Drone for medical products transportation in maternal healthcare: a systematic review and framework for future research. Medicine. 2020;99(36):e21967. doi:10.1097/MD.0000000000021967

50. Homier V, Brouard D, Nolan M, et al. Drone versus ground delivery of simulated blood products to an urban trauma center: the Montreal Medi-Drone pilot study. J Trauma Acute Care Surg. 2021;90 (3):515-521. doi:10.1097/TA.0000000000002961

51. Giroir BP. The opioid epidemic and emerging public health policy priorities. American Medical Association National Advocacy Conference; February 13, 2019; Washington, DC; 2019.

52. Ornato JP, You AX, McDiarmid G, et al. Feasibility of bystander-administered naloxone delivered by drone to opioid overdose victims. Am J Emerg Med. 2020;38(9):1787-1791. doi:10.1016/ j.ajem.2020.05.103

53. Beck S, Bui TT, Davies A, et al. An evaluation of the drone delivery of adrenaline auto-injectors for anaphylaxis: pharmacists' perceptions, acceptance, and concerns. Drones. 2020;4(4):1-22. doi:10.3390/drones4040066

54. Mateen FJ, Leung KHB, Vogel AC, Cissé AF, Chan TCY. A drone delivery network for antiepileptic drugs: a framework and modelling case study in a low-income country. Trans R Soc Trop Med Hyg. 2020;114(4):308-314. doi:10.1093/trstmh/trz131

55. Hii MSY, Courtney P, Royall PG. An evaluation of the delivery of medicines using drones. Drones. 2019;3(3):1-20. doi:10.3390/ drones3030052

56. McRae JN, Nielsen BM, Gay CJ, Hunt AP, Nigh AD. Utilizing drones to restore and maintain radio communication during search and rescue operations. Wilderness Environ Med. 2021;32(1):41-46. doi:10.1016/j.wem.2020.11.002

57. Liu C, Szirányi T. Real-time human detection and gesture recognition for on-board UAV rescue. Sensors (Basel, Switzerland). 2021;21(6):2180.

58. Podsiadło P, Bargiel B, Moskal W. Mountain rescue operations facilitated with drone usage. High Alt Med Biol. 2019;20(2):203. doi:10.1089/ham.2018.0149

59. Van Tilburg C. First report of using portable unmanned aircraft systems (drones) for search and rescue. Wilderness Environ Med. 2017;28(2):116-118. doi:10.1016/j.wem.2016.12.010

60. Snow Safe. Mountain rescue drones saving skiers lives from Avalanches; 2021. Available from: https://www.snowsafe.co.uk/ mountain-rescue-drones/. Accessed September 30, 2021.
61. Karaca Y, Cicek M, Tatli O, et al. The potential use of unmanned aircraft systems (drones) in mountain search and rescue operations. Am J Emerg Med. 2018;36(4):583-588. doi:10.1016/j.ajem.2017.09.025

62. Claesson A, Schierbeck S, Hollenberg J, et al. The use of drones and a machine-learning model for recognition of simulated drowning victims - a feasibility study. Resuscitation. 2020;156:196-201. doi:10.1016/j.resuscitation.2020.09.022

63. Bhatt K, Pourmand A, Sikka N. Targeted applications of unmanned aerial vehicles (drones) in telemedicine. Telemed J E Health. 2018;24 (11):833-838. doi:10.1089/tmj.2017.0289

64. Seguin $C$, Blaquière $G$, Loundou $A$, Michelet $P$, Markarian $T$. Unmanned aerial vehicles (drones) to prevent drowning. Resuscitation. 2018;127:63-67. doi:10.1016/j. resuscitation.2018.04.005

65. Claesson A, Svensson L, Nordberg P, et al. Drones may be used to save lives in out of hospital cardiac arrest due to drowning. Resuscitation. 2017;114:152-156. doi:10.1016/j.resuscitation.201 17.01 .003

66. Greenwood F, Nelson EL, Greenough PG, Ganguly AR. Flying into the hurricane: a case study of UAV use in damage assessment during the 2017 hurricanes in Texas and Florida. PLoS One. 2020;15(2): e0227808. doi:10.1371/journal.pone.0227808

67. Sharma G. Armed with drones, aid workers seek faster response to earthquakes, floods; 2016. Available from: https://www.reuters.com/ article/us-humanitarian-summit-nepal-drones/armed-with-drones-aidworkers-seek-faster-response-to-earthquakes-floodsidUSKCN0Y7003. Accessed September 30, 2021.

68. Chuang CC, Rau JY, Lai MK, Shih CL. Combining unmanned aerial vehicles, and internet protocol cameras to reconstruct 3-D disaster scenes during rescue operations. Prehosp Emerg Care. 2019;23 (4):479-484. doi:10.1080/10903127.2018.1528323

69. Volansi I. Drone supply delivery trials to Ocracoke Island underway; 2021. Available from: https://volansi.com/drone-supply-deliverytrials-to-ocracoke-island-underway/. Accessed September 20, 2021.

70. Clark DG, Ford JD, Tabish T, Cheungpasitporn W. What role can unmanned aerial vehicles play in emergency response in the Arctic: a case study from Canada. PLoS One. 2018;13(12):e0205299. doi:10.1371/journal.pone.0205299

71. Jain T, Sibley A, Stryhn H, Hubloue I. Comparison of unmanned aerial vehicle technology versus standard practice in identification of hazards at a mass casualty incident scenario by primary care paramedic students. Disaster Med Public Health Prep. 2018;12 (5):631-634. doi:10.1017/dmp.2017.129

72. Sibley AK, Jain TN, Butler M, et al. Remote scene size-up using an unmanned aerial vehicle in a simulated mass casualty incident. Prehosp Emerg Care. 2019;23(3):332-339. doi:10.1080/10903127 .2018 .1511765

73. Hart A, Chai PR, Griswold MK, Lai JT, Boyer EW, Broach J. Acceptability and perceived utility of drone technology among emergency medical service responders and incident commanders for mass casualty incident management. Am J Disaster Med. 2017;12 (4):261-265. doi:10.5055/ajdm.2017.0279

74. Álvarez-garcía C, Cámara-Anguita S, López-Hens JM, et al. Development of the aerial remote triage system using drones in mass casualty scenarios: a survey of international experts. PLoS One. 2021;16(5):e0242947. doi:10.1371/journal.pone.0242947

75. Sanfridsson J, Sparrevik J, Hollenberg J, et al. Drone delivery of an automated external defibrillator - a mixed method simulation study of bystander experience. Scand J Trauma Resusc Emerg Med. 2019;27(1):40. doi:10.1186/s13049-019-0622-6

76. Carter H, Drury J, Rubin GJ, Williams R, Amlôt R. Applying crowd psychology to develop recommendations for the management of mass decontamination. Health Secur. 2015;13(1):45-53. doi:10.1089/ hs.2014.0061 
77. Lum MJ, Rosen J, King H, et al. Telesurgery via Unmanned Aerial Vehicle (UAV) with a field deployable surgical robot. Stud Health Technol Inform. 2007;125:313-315.

78. Rosser JC, Wood M, Payne JH, et al. Telementoring. A practical option in surgical training. Surg Endosc. 1997;11(8):852-855. doi: $10.1007 / \mathrm{s} 004649900471$

79. Balasingam M. Drones in medicine-The rise of the machines. Int J Clin Pract. 2017;71(9):e12989. doi:10.1111/ijcp.12989

80. Vincenzi D, Ison D, Liu D. Public perception of Unmanned Aerial Systems (UAS): a survey of public knowledge regarding roles, capabilities, and safety while operating within the National Airspace System (NAS); 2013. Available from: https://commons.erau.edu/pub lication/639/. Accessed November 3, 2021.

81. Clothier RA, Greer DA, Greer DG, Mehta AM. Risk perception and the public acceptance of drones. Risk Anal. 2015;35(6):1167-1183. doi: $10.1111 /$ risa. 12330

82. Lieberman JD, Miethe TD, Troshynski EI, Heen M. Aerial Drones, Domestic Surveillance and Public Opinion of Adults in the United States. Research in Brief. Las Vegas, NV: Center for Crime and Justice Policy; 2014.

83. Resnik DB, Elliott KC. Using drones to study human beings: ethical and regulatory issues. Sci Eng Ethics. 2019;25(3):707-718. doi:10.1007/s11948-018-0032-6

84. Miethe TD, Lieberman JD, Sakiyama M, Troshynski EI. Public Attitudes About Aerial Drone Activities: Results of a National Survey. State Data Brief. CCJP 2014-02. Las Vegas, NV: Center for Crime and Justice Policy; 2014.

85. Khan SZ, Mohsin M, Iqbal W. On GPS spoofing of aerial platforms: a review of threats, challenges, methodologies, and future research directions. PeerJ Comput Sci. 2021;7:e507. doi:10.7717/peerj-cs.507

86. Marr B. 6 amazing passenger drone projects everyone should know about; 2018. Available from: https:/www.forbes.com/sites/bernardmarr/2018/ 03/26/6-amazing-passenger-drone-projects-everyone-should-know-about $/$ ?sh=97c19bb4ceb5. Accessed September 15, 2021.

87. Johnson JA, Svach MR, Brown LH. Drone and other hobbyist aircraft injuries seen in U.S. emergency departments, 2010-2017. Am J Prev Med. 2019;57(6):826-829. doi:10.1016/j.amepre.2019.06.023

88. Newton C. Inside the test flight of Facebook's first internet drone; 2016. Available from: https:/www.theverge.com/a/mark-zuckerberg-future-offacebook/aquila-drone-internet. Accessed September 15, 2021.

89. Zègre-Hemsey JK, Grewe ME, Johnson AM, et al. Delivery of automated external defibrillators via drones in simulated cardiac arrest: users' experiences and the human-drone interaction. Resuscitation. 2020;157:83-88. doi:10.1016/j.resuscitation.2020.10.006
90. Engineers Australia. Passenger-carrying drones now a reality; 2016. Available from: https://www.engineersaustralia.org.au/News/passen ger-carrying-drones-now-reality. Accessed September 24, 2021.

91. Karam N, Jost D, Jouven X, Marijon E. Automated external defibrillator delivery by drones: are we ready for prime time? Eur Heart J. 2021. doi:10.1093/eurheartj/ehab565

92. Long AS, Hanlon AL, Pellegrin KL. Socioeconomic variables explain rural disparities in US mortality rates: implications for rural health research and policy. SSM Popul Health. 2018;6:72-74. doi:10.1016/j.ssmph.2018.08.009

93. Parker K, Horowitz JM, Brown A, Fry R, D’Vera C, Igielnik R. Demographic and economic trends in urban, suburban and rural communities; 2018. Available from: https://www.pewsocialtrends. org/2018/05/22/demographic-and-economic-trends-in-urbansuburban-and-rural-communities/. Accessed July 27, 2020.

94. van Nieuwenhuizen BP, Oving I, Kunst AE, et al. Socio-economic differences in incidence, bystander cardiopulmonary resuscitation and survival from out-of-hospital cardiac arrest: a systematic review. Resuscitation. 2019;141:44-62. doi:10.1016/j.resuscitation.2019.05.018

95. Hsia RY, Huang D, Mann NC, et al. A US national study of the association between income and ambulance response time in cardiac arrest. JAMA Netw Open. 2018;1(7):e185202. doi:10.1001/ jamanetworkopen.2018.5202

96. Chan PS, McNally B, Vellano K, Tang Y, Spertus JA. Association of neighborhood race and income with survival after out-of-hospital cardiac arrest. J Am Heart Assoc. 2020;9(4):e014178. doi:10.1161/ JAHA. 119.014178

97. Sasson C, Magid DJ, Chan P, et al. Association of neighborhood characteristics with bystander-initiated CPR. N Engl J Med. 2012;367 (17):1607-1615. doi:10.1056/NEJMoa1110700

98. Andersen LW, Holmberg MJ, Granfeldt A, et al. Neighborhood characteristics, bystander automated external defibrillator use, and patient outcomes in public out-of-hospital cardiac arrest. Resuscitation. 2018;126:72-79. doi:10.1016/j.resuscitation.2018.02.021

99. Tarantola A. Rural North Carolina residents will soon get their meds delivered by drone; 2020. Available from: https://www.engadget. com/rural-north-carolinians-will-soon-get-their-meds-delivered-bydrone-100030615.html?guccounter=1. Accessed September 25, 2021.
Open Access Emergency Medicine

\section{Publish your work in this journal}

The Open Access Emergency Medicine is an international, peerreviewed, open access journal publishing original research, reports, editorials, reviews and commentaries on all aspects of emergency medicine. The manuscript management system is completely online and includes a very quick and fair peer-review system, which is all easy to use. Visit http://www.dovepress.com/testimonials.php to read real quotes from published authors. 